\title{
UPTAKE AND RETENTION OF MALATHION BY THE CARP
}

\author{
Michael E. Bender \\ Department of Environmental Health, University of Michigan \\ Ann Arbor, Michigan 48104
}

AS ORGANOPHOSPHATE INSECTICIDES are being used extensively in all phases of pest control, these compounds frequently reach the aquatic environment. This occurs most directly through spraying operations for mosquitoes, and indirectly as a result of runoff from treated land areas. Also, these compounds have been suggested for possible use in fish management, for fish eradication (Mulla et al., 1967); and mixtures of two of the phosphates--malathion and naled--have been used as a selective piscicide (Hoff and Westman, 1965).

The stated "safety" of these phosphate compounds as opposed to those of hydrocarbon origin has been based upon both acute toxicity' studies and the length of persistence of the parent compound in the environment. Acute toxicity levels of the phosphate insecticides to fish have been shown by Tarzwell (1959) to be considerably lower than those of the hydrocarbons. The variable rate of hydrolysis of the phosphate compounds, however, presents several difficulties in the assumption of rapid breakdown.

The purpose of this investigation was to study the uptake and retention of one of these pesticides by the carp, Cyprinus carpio. The compound chosen for investigation was malathion, a phosphorothioate developed by the American Cyanamid Company in 1950.

These investigations were supported by U.S. Public Health Service Research Grant ES-00016-02 to Rutgers University.
Weiss and Gakstatter (1965) have shown that the persistence of malathion in aqueous solutions is dependent on $\mathrm{pH}$. The half-life of this material in solution of ph 6,7 , and 8 ranged from 3 months to 1 week. As the results of these investigators show, malathion certainly could exist in the environment long enough to permit its uptake by aquatic animals. Possible consequences from the uptake of the compound include: (1) the establishment--in edible portions of fish--of residue levels exceeding the limits established by the Food and Drug Administration for other edible meats, and (2) creation of conditions which could result in biological concentration of this compound through the food chain.

The specific objectives of this study on uptake and retention were to determine: (1) the rate of uptake of malathion from water, (2) the relative concentration of the pesticide in various tissues, (3) the differences between aqueous and oral uptake, (4) the relation between the aqueous concentration of the pesticide and the amount of uptake, and (5) the retention time of the pesticide residue.

\section{Me thods}

The carp was preferred to other species as an experimental animal because of its pharyngeal teeth, which, when closed, function as a locking mechanism so that material placed in the foregut cannot be regurgitated. Kelly (1959) developed the methods used here for holding the fish and feeding them capsules filled with toxicant. 
The exposure experiments were conducted in two 200-liter polyethylene tanks, and the treatments were allocated to various time periods as in an incomplete block design. In the studies on aqueous uptake, an aqueous concentrate of malathion was added to a tank filled to within 5 gallons of capacity. This concentrate was prepared by mixing small portions of an acetone stock solution vigorously with water. Aqueous concentrations were maintained at the test levels by replenishing half of the tank volume every 24 hours with a new solution. Concentrations were checked by extraction of water samples with hexane and subsequent analysis in the gas chromatograph.

Two investigations using the format described above were conducted to determine: (1) the relation between aqueous malathion concentration and amount of uptake, and (2) the effect of exposure time on the amount of uptake.

To investigate the length of residue persistence in carp flesh, 36 fish--in 3 groups of 12 fish each--were exposed to a concentration of 5 milligrams per liter for 4 days. After this exposure, fresh water was flushed through the exposure tank at a rate of 1 liter per minute, and two fish were removed for analysis at $0,12,24,48,72$, and 96 hours.

Malathion uptake by way of the digestive tract was studied by inserting into the foregut of the fish a gelatin capsule filled with the compound. In each of two trials, four experimental animals weighing approximately 2 pounds each were fed capsules containing 200 milligrams of pure malathion. These fish were then placed in a tank with control fish (that is, fish that had not been fed malathion), and fresh water was flushed through the tank at a rate of 50 liters per hour. After a 24-hour exposure, the fish were sacrificed for analysis.

Malathion was extracted from the various tissues by grinding them with hexane ( 3 parts hexane, 1 part tissue) in a homogenizer or in glass tissue blenders for the smaller samples of brain and liver. The extracts were cleaned by chromatographing them on a prewashed florisil column prepared with petroleum ether and eluting the malathion from the column with acetone.

Quantitative measurements for all the malathion extracts were made by comparing the peak area of malathion standards from the gas chromatograph with those of the extracts.

\section{$\underline{\text { Results and Discussion }}$}

The location of pesticide residues in various tissues is of considerable importance, whether the main interest be practical or theoretical. From the practical viewpoint, it is most important to determine the level of residue in edible portions of the species. Theoretical considerations would include relation of the concentrations to site of action or breakdown as well as possible storage sites. These considerations prompted a study on the location of malathion residues in fish exposed to 5 milligrams per liter in the aqueous uptake experiments. Table 1 shows the results of these tissue analyses. The results given here are corrected for percent of recovery as determined from studies using spiked samples. The wide confidence intervals on most of these tissues probably are due to variability in the level of interfering substances that the cleanup procedure failed to eliminate.

The results did reveal, however, that the liver was the organ having the highest concentration of residue, and that flesh, blood, gills, and brain (in that order) had

TABLE 1.--Distribution of tissue residues in $f$ ish exposed to 5 milligrams per liter for 4 days

[Confidence 1 imits at 95-percent level]

\begin{tabular}{|c|c|}
\hline Tissue & $\begin{array}{l}\text { Residue } \\
\text { (ug./g.) }\end{array}$ \\
\hline 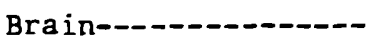 & $2.58 \pm 1.94$ \\
\hline 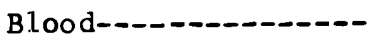 & $4.97 \pm 4.30$ \\
\hline 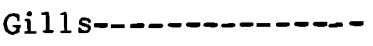 & $3.23 \pm 2.82$ \\
\hline 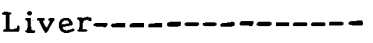 & $66.59 \pm 25.00$ \\
\hline F1esh------ - - - - - - - & $28.43 \pm 5.11$ \\
\hline
\end{tabular}


decreasing concentrations. Casida (1964) stated that the primary organ involved in the breakdown of organic phosphates in mammals is the liver. The high concentration of malathion found in samples of liver in this study suggests that the liver has a similar function in fishes. Meyer (1965) found concentrations of Guthion $\mathbb{B}$ approximately double that of flesh samples in the offal (that is, combined samples of the digestive organs) of catfish. These results suggest that the bulk of the residue probably was in the liver portions of his samples.

The results of the experiments relating exposure concentration to uptake level are shown in table 2, and the level of uptake in these flesh samples is shown in figure 1 as a function of concentration. Although the data obtained on uptake were limited, the shape of the uptake curve gives a good indication of the relation between amount of uptake and level of exposure. Extension of exposure to lower levels probably would show an even greater lag in uptake, indicating a detoxification mechanism capable of eliminating most of the malathion taken up at low exposure levels.

The flesh of fish exposed for 4 days to malathion at a rate of 2.5 milligrams per liter showed residue levels in excess of those now established by the Food and Drug Administration for the meat of other animals. This level of exposure is very high for normal field conditions: the level that is recommended for mosquito control is about 0.5 milligram per liter, and it

TABLE 2.--Results of study relating aqueous exposure level to level of uptake

[Uptake in mg. $/ \mathrm{kg}$. of flesh]

\begin{tabular}{|c|c|c|c|}
\hline $\begin{array}{c}\text { Concentration } \\
\text { for 4-day } \\
\text { exposure } \\
\text { (mg./1.) } \\
\end{array}$ & $\overline{\mathrm{X}}$ & $\begin{array}{c}95 \text {-percent } \\
\text { confidence } \\
1 \text { imits }\end{array}$ & Corrected \\
\hline 1.0 & 0.92 & \pm 0.37 & 1.06 \\
\hline 2.5 & 7.91 & \pm 2.27 & 7.23 \\
\hline 5.0 & 28.43 & \pm 5.11 & 28.20 \\
\hline 7.5 & 41.65 & \pm 6.08 & 42.44 \\
\hline
\end{tabular}

seems unlikely that problems from high residues would arise under normal conditions of runoff.

The study on uptake levels and length of exposure is summarized in table 3 . The amount of malathion uptake is shown in figure 2 as a function of time. As has been noted in the study on the effect of concentration on uptake, the curve is sigmoid, showing a slight lag in initial uptake and later approaching a plateau. Equilibrium conditions were established after about 4 days of exposure to a level of 5 milligrams per liter. The significance of this observation is that in acid water, where the malathion could exist for long periods, it is unlikely that residue levels would increase constantly with length of exposure.

One of the important factors in the selection of a pesticide for field use is the length of its persistence as a residue in a material that is to be used as food. Persistence of residue was investigated in this study by determining the residual levels of malathion in flesh samples after exposure of the test animal to 5 milligrams per liter for 4 days. The results obtained in the study are shown in table 4, and the retention of malathion residues is shown in figure 3 as a function of time. The average half-life of a residue calculated from these data was 12 hours. Such a rapid rate of breakdown is of considerable significance, since the residue level

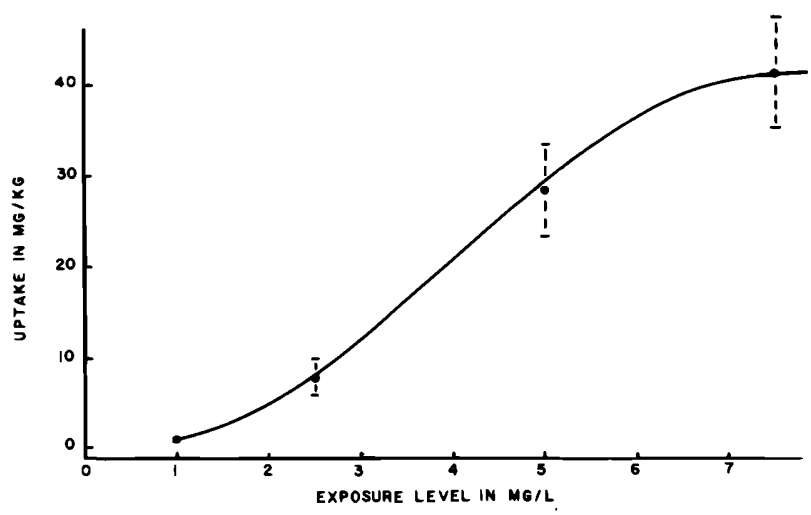

FIGURE 1.-- Exposure experiments relating exposure concentration to uptake level. 
TABLE 3.--Level of uptake as determined by period of exposure

[Uptake in mg. $/ \mathrm{kg}$. of flesh]

\begin{tabular}{crrrr}
\hline $\begin{array}{c}\text { Exposure to } \\
\begin{array}{c}5 \text { milligrams } \\
\text { per liter } \\
\text { (days) }\end{array}\end{array}$ & $\overline{\mathrm{X}}$ & $\begin{array}{c}\text { 95-percent } \\
\text { confidence } \\
\text { limits }\end{array}$ & $\begin{array}{c}\text { Corrected } \\
\overline{\mathrm{X}}\end{array}$ \\
\cline { 1 - 1 } \cline { 5 - 5 } \cline { 5 - 5 } & & & & \\
2 & 4.92 & \pm 0.47 & & 3.33 \\
4 & 11.97 & \pm 2.68 & & 12.04 \\
8 & 27.83 & \pm 4.40 & & 28.72 \\
& 31.26 & \pm 3.80 & & 31.87 \\
\hline
\end{tabular}

reached at this exposure level is some six times the limit recommended by the Food and Drug Administration for other meats.

These data make it seem safe to predict that even after exposure to extremely high field levels, the fish would metabolize the malathion taken up and could be eaten safely within a week. This would be possible if they were exposed to a single dose only, and if, because of hydrolysis or metabolism, the concentration in the water was lowered to at least 1 milligram per liter--a level which (figure 1) seems necessary for significant uptake.

Meyer (1965) showed a loss of similar rapidity with Guthion $B$ in catfish, except that those fish remained exposed to a field application during the study.

Gakstatter and Weiss (1967) conducted experiments on the half-life of several chlorinated hydrocarbons. Lindane, one of the compounds studied, had a half-life of approximately 18 hours.

Table 5 shows results of the study on oral uptake of malathion and the standard deviations calculated on the data. These

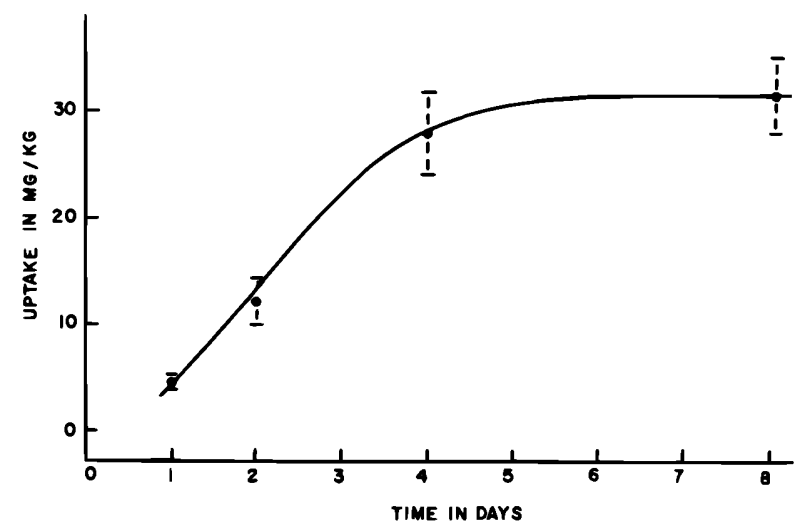

FIGURE 2.--Effect of exposure period on uptake level.

data indicate that the uptake by the intestinal tract does not contribute a significant amount to the malathion residue. Possible reasons for this include: (1) rapid hydrolysis in the foregut or intestinal cavities, (2) breakdown by biochemical

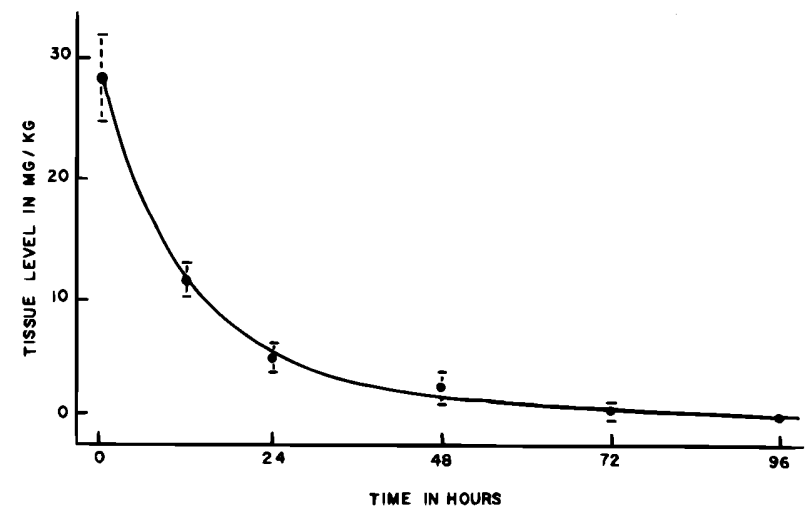

FIGURE 3.--Retention of malathion residues as a function of $t$ ime.

TABLE 4.--Results of study on retention of residue as a function of time

\begin{tabular}{|c|c|c|c|c|c|c|}
\hline & \multicolumn{6}{|c|}{ Time after exposure (in hours) } \\
\hline & 0 & 12 & 24 & 48 & 72 & 96 \\
\hline Mean (in mg. $\mathrm{kg}$. of $\mathrm{flesh}$ ) & 28.50 & 11.60 & 5.33 & 2.55 & 0.88 & 0.08 \\
\hline Confidence limits, 95\% & \pm 3.70 & \pm 1.48 & \pm 1.42 & \pm .80 & \pm .39 & \pm .80 \\
\hline
\end{tabular}


TABLE 5.--Results of study on oral exposure of $f$ ish to malathion

[Malathion concentration in $\mathrm{mg} . / \mathrm{kg}$. of flesh]

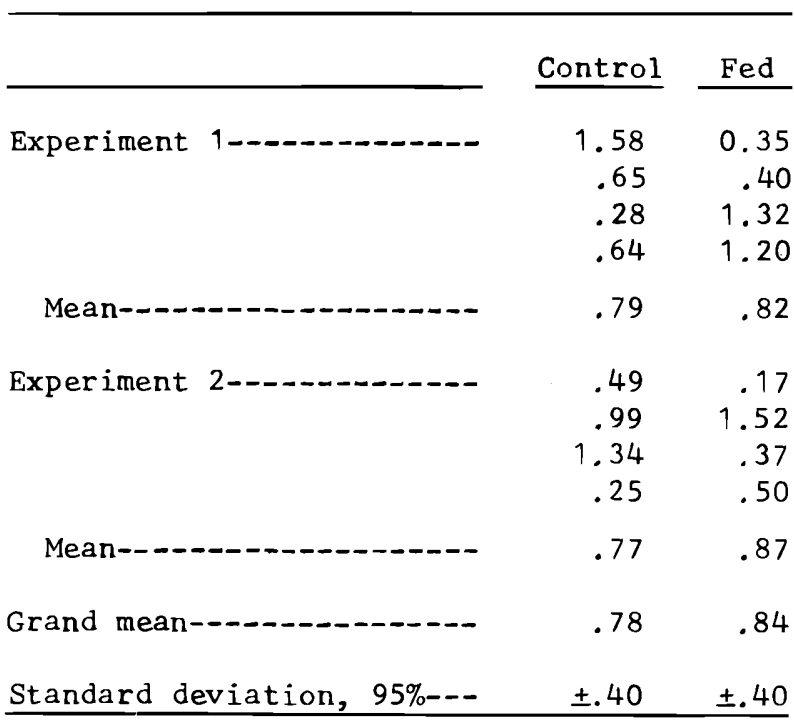

pathways, or (3) lack of uptake because of low permeability. Whatever the reason, it seems safe to conclude that the buildup of malathion in fish from the ingestion of contaminated food is unlikely--assuming that other fish species behave in a similar manner.

These results are particularly significant in view of the slow hydrolysis of malathion in neutral or slightly acid solutions. Here the compound could persist in the environment long enough to be concentrated by fish food organisms and to create a condition which: if uptake by ingestion were significant, could lead to further biological manifestation of the compound through the food chain.

\section{$\underline{\text { Literature }}$ Cited}

Casida, J. E.

1964. Esterase inhibitors as pesticides. Science, vol. 146, p. 1011-1017.

Gakstatter, J. L., and C. M. Weiss.

1967. The elimination of DDT-C 14 ,
dieldren-C ${ }^{14}$, and lindane-C $\mathrm{C}^{14}$ from fish following a single sublethal exposure in aquaria. Transactions of American Fisheries Society, vol. 96 , no. 3, p. 301-307.

Hoff, J. G., and J. R. Westman.

1965. Experiments with a Dibrommalathion formulation as a selective piscicide. New York Fish and Game Journal, vol. 12, no. 1, p. 99-107.

Kelly, W. H.

1959. A fish-holding device. New York Fish and Game Journal, vol. 6, p. 117-119.

Meyer, Fred P.

1965. The experimental use of $\mathrm{Gu}-$ thion ${ }^{\circledR}$ as a selective fish eradicator. Transactions of American Fisheries Society, vol. 94, no. 3, p. 203-209.

Mulla, M. S., J. St. Amant, and L. D. Anderson.

1967. Evaluation of organic pesticides for possible use as fish toxicants. Progressive FishCulturist, vol. 29, no. 1, p. 36-42.

Tarzwell, C. M.

1959. The toxicity of some organic insecticides to fishes. Proceedings of 12 th Annual Conference, Southeastern Association of Game and Fish Commissioners, 1958, p. 233-239.

Weiss, C. M., and J. L. Gakstatter. 1965. The decay of anticholinesterase activity of organic phosphorus insecticides on storage in waters of different $\mathrm{pH}$. Proceedings of the Second International Water Pollution Research Conference, Tokyo, 1964, p. 83-95. 